American Journal of Biochemistry and Biotechnology 3 (3): 131-140, 2007

ISSN 1553-3468

(C) 2007 Science Publications

\title{
Importance of blood gas measurements in perinatal asphyxia and alternatives to restore the acid base balance status to improve the newborn performance
}

\author{
${ }^{1}$ H. Orozco-Gregorio, ${ }^{2}$ D. Mota-Rojas, ${ }^{2} \mathrm{M}$. Alonso-Spilsbury, ${ }^{2} \mathrm{M}$. González-Lozano, \\ ${ }^{3}$ M. Trujillo-Ortega, ${ }^{2}$ S.A. Olmos-Hernández, ${ }^{2}$ P. Sánchez-Aparicio, ${ }^{2}$ R. Ramírez-Necoechea, \\ ${ }^{4}$ R. Hernández-González, ${ }^{5}$ R. Uribe-Escamilla and ${ }^{6} \mathrm{D}$. Villanueva-García \\ ${ }^{1}$ Postgraduate Division of Animal Science and Health, Faculty of Veterinary Medicine and Animal \\ Production, Universidad Nacional Autónoma de México, México DF, Mexico, \\ ${ }^{2}$ Department of Animal Production \& Agriculture, Área de Investigación; Ecodesarrollo de la Producción \\ Animal, Universidad Autónoma Metropolitana-Xochimilco, Mexico DF, Mexico. \\ ${ }^{3}$ Department of Animal Medicine and Production: Swine, Faculty of Veterinary and Animal Production, \\ Universidad Nacional Autónoma de México, Ciudad Universitaria. Mexico. \\ ${ }^{4}$ Department of Experimental Research and Animal Resources, Instituto Nacional de Ciencias Médicas y \\ Nutrición Salvador Zubirán. Mexico. \\ ${ }^{5}$ Laboratory of Neurochemicals. Instituto Nacional de Rehabilitación. México DF, México. \\ ${ }^{6}$ Division of Neonatology, Hospital Infantil de México "Federico Gómez", México DF, Mexico
}

\begin{abstract}
Prolonged or intermittent asphyxia in utero and during farrowing weakens piglets and renders them less capable of adaptation to extrauterine life. Piglets with lesser viability at birth have increased blood $\mathrm{pCO}_{2}$ and blood lactic acid concentrations and decreased blood $\mathrm{pH}$. Moreover, the ability to thermoregulate during an acute cold stress is inversely related to umbilical blood lactate concentrations. Blood gas measurements and noninvasive estimations provide important information about oxygenation. The general goals of oxygen therapy in the neonate are to maintain adequate arterial $\mathrm{PaO}_{2}$ and $\mathrm{SaO}_{2}$, and to minimize cardiac work and the work of breathing. Arterial blood gas determinations of $\mathrm{pCO}_{2}$ provide the most accurate determinations of the adequacy of alveolar ventilation. Blood gases obtained in the immediate perinatal period can help assess perinatal asphyxia, but particular attention must be paid to the sampling site, the time of life, and the possible and proven diagnoses. The decision to obtain blood gases must be weighed by the individual clinician against the potential benefits. Current measures for restoring the acid base balance status in the newborn with perinatal asphyxia are discussed.
\end{abstract}

Key words: hypoxia, gases exchange, acidaemia, oxygen deficiency, piglet

\section{INTRODUCTION}

Improved understanding of hemoglobin-oxygen interactions and gas exchange, which occurred in the $1950 \mathrm{~s}$ and $1960 \mathrm{~s}$ and were applied to neonatal care, provided a cornerstone for later clinical successes. Blood gas measurements permitted the diagnosis of metabolic and respiratory acidosis associated with the birth process and with postnatal adaptation to air breathing ${ }^{[1]}$.

The cardiovascular system undergoes changes just as dramatic, with conversion from two circulations in parallel to two circulations now in series after birth, respiratory gas exchange, formerly a placental function, must be established by the lungs within minutes. Therefore, frequent and serious difficulties in cardiorespiratory adaptation in the perinatal and neonatal periods are not surprising. Although the metabolic acidosis found in cord blood is a poor predictor of longterm neurological injury, assessment of umbilical cord blood gas is helpful to exclude intra-partum or birth events that cause acidosis and serves as legal evidence against any alleged association with poor outcome ${ }^{[2]}$, there is a progression of risk in term infants for Apgar

Corresponding Author: D. Mota-Rojas, Ph D. Department of Animal Production \& Agriculture, Universidad Autónoma Metropolitana-Xochimilco. Calzada del Hueso 1100. Col. Villa Quietud. Del. Coyoacán. 04960. México D.F. Mexico Tel/Fax: (525) 54837535 
less than 7 at 5 minutes, neonatal intensive care unit admission, and need for assisted ventilation with worsening acidosis at birth, which begins with cord blood values close to mean values indicating a higher threshold for associated acidaemia with these outcomes than is seen for more severe neonatal outcomes ${ }^{[3]}$. Although a 5-minute Apgar of $\leq 3$ has been shown to be a good predictor of neonatal death, low 1- and 5-minute Apgar scores in infants who survive, correlate poorly with intra-partum asphyxia and are poor predictors of long-term neurologic outcome ${ }^{[4,5]}$.

The events that occur after acute asphyxia, such as metabolic acidosis and hypoxia are often features in pigs, they interact with its postnatal behaviour and thermorregulation, prolonging the time interval between birth and first udder contact and sucking with a smaller colostrum intake, an inadequate immune status, and a decreasing corporal temperature with their consequent lower viability. More studies are necessary to evaluate during piglet's birth; foetal stress, acid-base and energy metabolism status, both tools seem to be good options in pig obstetrics. On the other hand, apparently several other factors that also cause perinatal asphyxia could be "the effect", for example; meconium aspiration syndrome. During asphyxia, blood redistribution from the intestine to vital organs causes an increase of intestinal peristalsis and relaxation of the anal sphincter. These two responses to hypoxia eventually lead to the discharge of meconium into the amniotic fluid. If anoxia persists, increased respiratory movements with an opened glottis results in aspiration of amniotic fluid contaminated with meconium into the lung. Studies of correlation between the diverse methods must be made to quantify the vigor of a piglet: the latency to first suckling, the heart and respiratory rate, the muscular tone and other parameters. Hypoxia, genetic, endocrine, birth-weight and the environmental factors can decrease the vigor of the newborn pig.

\section{IMPORTANCE OF BLOOD GAS TEST IN PERINATOLOGY}

The clinical application of blood gas analysis and pulse oximetry is regulated in the United States by the Joint Commission on Accreditation of Healthcare Organizations (JCAHO). However, JCAHO requires compliance with the guidelines of other groups, primarily the Clinical and Laboratory Standards Institute (CLSI) and its predecessor NCCLS, prior to accrediting an institution. Relevant to this discussion, these guidelines focus on measurement via analytical instruments, such as analyzers for measurement of blood CO-oximetry, gas and $\mathrm{pH}$. These guideline documents primarily describe principles for collecting, handling, transporting, and analyzing arterial blood specimens, as well as instrument quality control matters, with the aims of reducing collection hazards, ensuring integrity of the arterial specimen, and achieving reliable data. Pulse oximetry $(\mathrm{SpO} 2)$ values are not a direct measure of the percent of arterial hemoglobin saturated with oxygen. The current pulse oximeters in neonatal use cannot differentiate nor quantify dyshemoglobins. It is important to note that the calculated arterial oxygen saturation $(\mathrm{SaO} 2)$ value reported trhough a blood gas analyzer is not a reference for $\mathrm{SpO} 2$. Rather, only the functional $\mathrm{SaO} 2$ value from $\mathrm{CO}$-oximeter analysis of an arterial blood specimen can provide a reference for $\mathrm{SpO}$. The CO-oximeter also provides a measure of the content of fetal versus adult hemoglobin.

In human perinatology, blood gas measurements: oxygen pressure $\left(\mathrm{pO}_{2}\right)$, carbon dioxide pressure $\left(\mathrm{pCO}_{2}\right)$ and $\mathrm{pH}$ with other complementary techniques by noninvasively monitoring, provide essential information to evaluate neonate's oxygenation ${ }^{[6]}$ to make correct diagnosis and therapeutic decision. Umbilical artery values of blood gas measurements also serve to identify high risk newborns, and they provide a useful tool to evaluate and to preserve the neonatal health during the birth ${ }^{[7]}$. A long established measure of the degree and duration of foetal hypoxia has been blood $\mathrm{pH}$, drawn either from the scalp or the cord, a practice carried into newborn care with $\mathrm{pH}$ analysis of heel puncture blood. Because of the stability of this value, factors such as the length of sampling time, the degree of exposure to air, and mixing of blood sources (arteriolar, capillary and venous) have little affect on measurement accuracy. Repeated arterial stabs are strongly discouraged, as they are painful and do not represent oxygenation as well as pulse oximetry. Arterial stabs may be taken from the radial artery (provided there is also a palpable ulnar pulse) or from the brachial artery, although this is in close proximity to the median nerve. All three specimens will give a good assessment of acid-base status and $\mathrm{pCO}_{2}$, whereas arterial specimens are required to assess $\mathrm{pO}_{2}$. It is always important to note the percentage of inspired oxygen when interpreting blood gases.

Also in veterinary medicine, high lactate concentration in umbilical cord blood at birth is an indicator of hypoxia, and increases with the birth duration ${ }^{[8]}$. Indeed, stillborn piglets and piglets with low viability, caused by hypoxia during parturition show increased contents of lactate, glucose, $\mathrm{pCO}_{2}$, adrenalin and noradrenalin in blood ${ }^{[9]}$. Moreover, van Dijk et al. ${ }^{[10]}$ recently demonstrated that there is a clear 

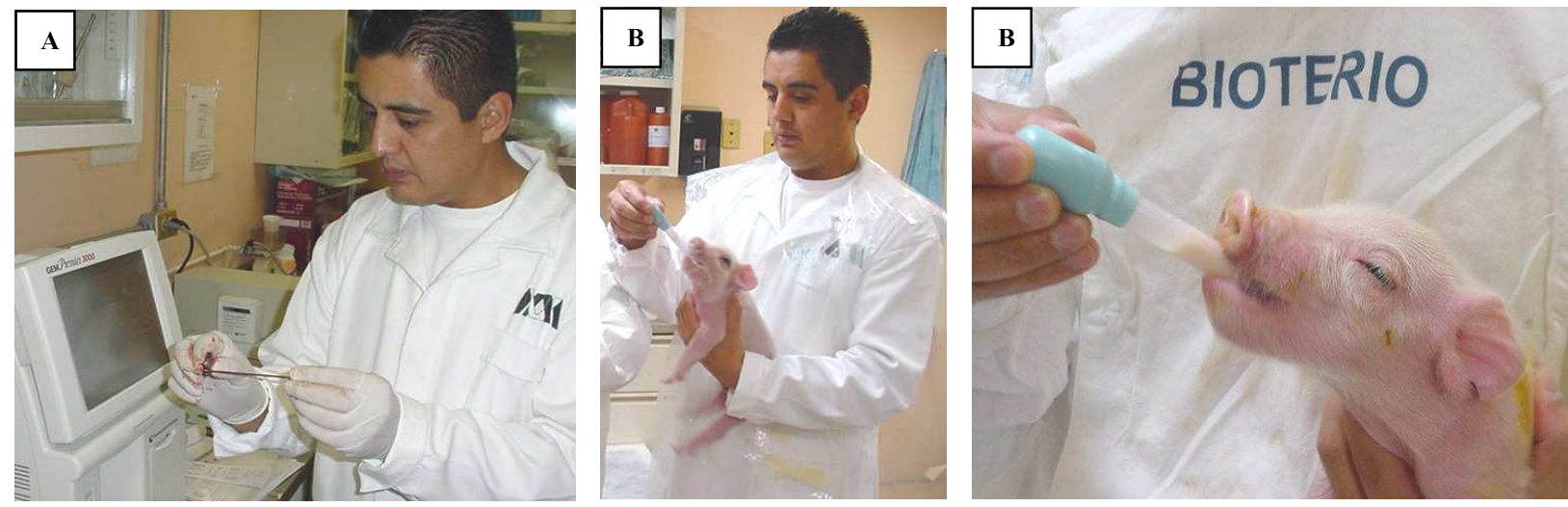

Fig. 1A: Measuring blood critical figures with a blood gas analyzer (GEM Premier 3000, I.L. Diagnostics). 1B. Newborn piglets with an acidaemia process were fed with milk replacer in laboratory conditions.
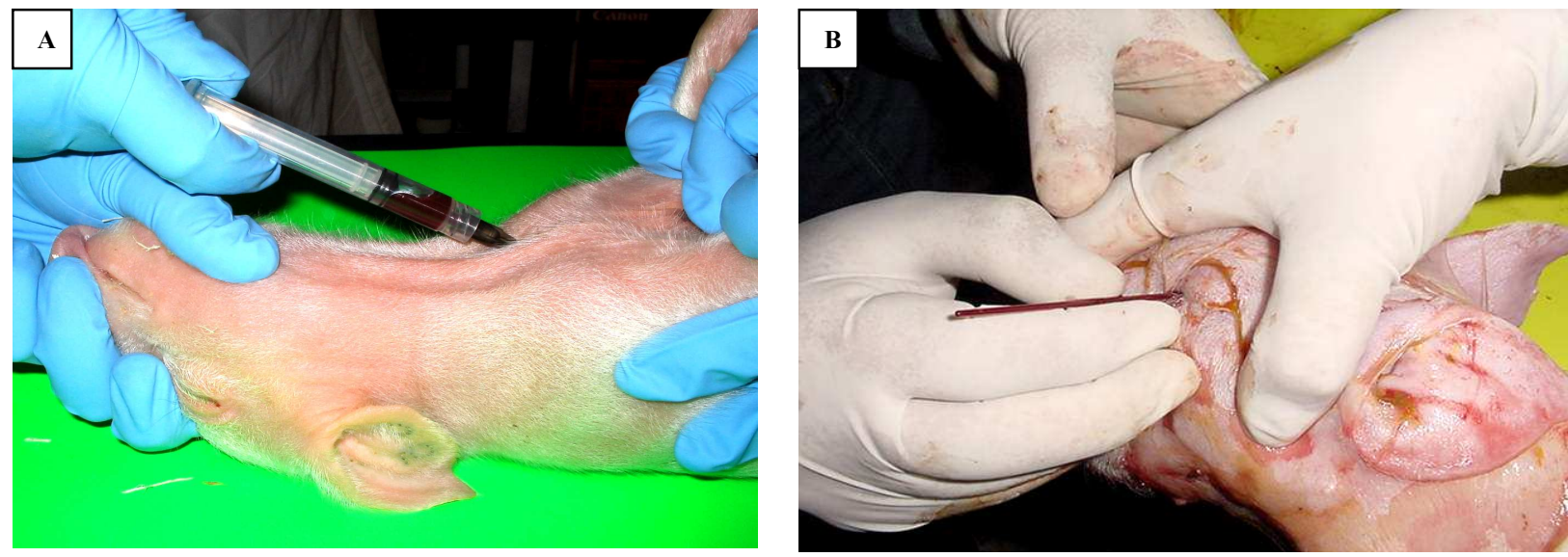

Fig. 2A: Taking a blood sample from the cava vein in a neonate pig. 2B. Blood sampling from the retroorbital venous sinus in a newborn piglet.

relation between factors affecting the progress of delivery and acid-base balance values in a polytocous species like the pig; piglets born with ruptured umbilical cords showed significantly lower $\mathrm{pH}$ values.

According to González de Dios [11], the pathophysiological definition of perinatal asphyxia in not operative in the clinical practice since several criteria have been proposed (abnormalities in electronic foetal monitoring, meconium-stained amniotic fluid, metabolic acidaemia, low Apgar score, etc.), with differences in the number and combination of criteria, and also in the cut-off points of quatitative variables. Furthermore, in many cases, the interpretation of acidbase disorders may be complicated by the mixed metabolic and respiratory origins of the disorder ${ }^{[12]}$. In the present analysis, emphasis is given in metabolic acidaemia. Acidosis means a high hydrogen ion concentration in the tissues. Acidaemia refers to a high hydrogen ion concentration in the blood and is the most easily measured indication of tissue acidosis. Other indices sometimes used to assess acidosis are the base excess or bicarbonate $\left(\mathrm{HCO}_{3}{ }^{-}\right)^{[13]}$. Nevertheless, these techniques of evaluation were exclusive of the human medicine, in recent studies Orozco et al. (unpublished data), reported that blood gas test has been used successfully in the area of large animal perinatology (Fig. 1A, 1B).

Acid-Base Status, Blood Gas, Temperature And Metabolic Profile Of The Newborn With Perinatal Asphyxia: The foetus depends on the mother for placental exchange of oxygen and carbon dioxide. This in turn relies on adequate maternal blood gas concentrations, uterine blood supply, placental transfer 
and fetal gas transport. Disruption of any of these can cause fetal hypoxia, which, despite compensatory mechanisms, may lead to acidosis ${ }^{[13]}$. During the stress of normal labor, some tissue hypoxia and placental insufficiency occur, resulting in a mixed respiratory and metabolic acidosis. After birth, as pulmonary gas exchange is established, $\mathrm{pCO}_{2}, \mathrm{pH}$, and $\mathrm{pO}_{2}$ values move toward normal adult values; the largest changes occur in the first few minutes after birth. Perinatal asphyxia occurs when there is inadequate placental gas exchange to meet ongoing foetal tissue needs for oxygen consumption and carbon dioxide elimination. The combination of lactic acidosis, the product of anaerobic metabolism, and $\mathrm{CO}_{2}$ accumulation results in a mixed acidosis. When insufficient oxygen is provided to tissues, hypoxia leads to metabolic acidosis. Thus, blood gas measurements, specifically $\mathrm{pO}_{2}, \mathrm{SaO}_{2}, \mathrm{pH}$, and base excess, can help to assess patient oxygenation, but must be combined with other clinical and laboratory assessments to provide a comprehensive picture. It is worth mentioning that current work suggests that only 10 to $20 \%$ of cerebral palsy cases is accounted for by perinatal asphyxia [6]. As carbohydrates, fat, and proteins are metabolized in the cell to produce energy, hydrogen ions and carbon dioxide are released as waste products. Metabolism in the presence of oxygen is called aerobic metabolism. In this process, hydrogen ions combine with oxygen to form water, and carbon dioxide combines with water to form carbonic acid. In adults, carbonic acid is transformed back into carbon dioxide in the lungs and excreted on exhalation; thus, the lungs are the main regulator of acid-base balance in the body. The foetus, however, depends on maternal and placental circulation for the delivery of oxygen and the removal of the waste products of metabolism, including carbon dioxide. In the absence of oxygen, cells can continue to produce energy, but this process, called anaerobic metabolism, cannot be maintained over the long term. When oxygen is not present to accept hydrogen ions, they form organic acids such as lactic acid. Buildup of organic acid changes the $\mathrm{pH}$ within the cells, and if this process continues too long, the $\mathrm{pH}$ will decrease to levels that result in cellular death $^{[14,15]}$.

Umbilical cord blood acid-base status at birth is regarded as important for evaluation of the newborn's condition. As an outcome variable, cord blood metabolic acidosis implies an increased risk of developing later motor and cognitive defects. However, there is no consensus on the $\mathrm{pH}$ definition of acidosis. In Sweden, traditionally a cord artery $\mathrm{pH}$ of less than 7.10 is considered indicative of foetal acidaemia. This value corresponds to the mean value minus two standard deviations. Other authors have used an index value of 7.20 , whereas a cut off at 7.00 seems to represent a critical limit for the risk of neonatal death or neurologic handicap. The American College of Obstetricians and Gynecologists, supports the use of an arterial $\mathrm{pH}$ of less than 7.00 as a clinically useful cut off ${ }^{[16]}$. A study by Belai et al. ${ }^{[17]}$ report that in infants with a $\mathrm{pH}$ of $<7$, an arteriovenous $\mathrm{pCO}_{2}$ difference of $>25 \mathrm{~mm} \mathrm{Hg}$ is a sensitive and specific parameter for identifying asphyxiated infants most likely to develop seizures, hypoxic-ischemic encephalopathy, and other abnormalities in the neonatal period. Arteriovenous $\mathrm{pO}_{2}$ differences were less sensitive in the detection of neonatal morbidity than arteriovenous $\mathrm{pCO}_{2}$ differences. Buthani ${ }^{[18]}$ reported the following mother, foetal and newborn blood gas values: mother (second trimester), a $\mathrm{pH}$ of 7.45, $\mathrm{PaO}_{2} 80-95 \mathrm{mmHg}, \mathrm{pCO}_{2} 34 \mathrm{mmHg}$; foetus (before labour) $\mathrm{pH}$ 7.35-7.40, $\mathrm{PaO}_{2}<25 \mathrm{mmHg}$ in pulmonary artery, $\mathrm{pCO}_{2} 40-42 \mathrm{mmHg}$; newborn (before first breath) $\mathrm{pH} 7.10-7.30, \mathrm{PaO}_{2} 16-18 \mathrm{mmHg}, \mathrm{pCO}^{2}$ 45-65 mmHg, and newborn (at about 6 hours) $\mathrm{pH} 7.35-$ 7.40, $\mathrm{PaO}_{2} 80-95 \mathrm{mmHg}, \mathrm{pCO}_{2} 34 \mathrm{mmHg}$.

In the case of polytocous species, as the pig, a broad range of acid-base values can be expected at birth in different members of the same litter [19,20]. Furthermore, a great variety exists as to the site where blood sampling of newborn piglets took place [carotid artery, vena cava cranialis (Fig. 2A), umbilical cord, or suborbital sinus blood (Fig. 2B).

Herpin et al. [21] induced asphyxia in piglets, consisting of the prevention of breathing within the first four minutes of life. After the treatment and 24 hours later, heat production capacity, shivering intensity and rectal temperature were measured 10 degrees Celsius below thermoneutrality. Effects on blood gas parameters were severe but transient whereas alterations in carbohydrate metabolism were maintained during the first $75 \mathrm{~min}$. This results suggested that the lower viability usually reported for piglets suffering from asphyxia during delivery is most likely to result from reduced vigour and colostrum intake, as well as altered carbohydrate metabolism early after birth.

In postnatal medicine, acidosis is often described as respiratory (predominantly due to increased $\mathrm{pCO}_{2}$ ) or metabolic (predominantly due to increased lactic acid). However, while acute foetal acidosis is almost always initially respiratory, this is quickly followed by mixed respiratory and metabolic acidosis if there is no improvement in oxygenation The major sources of hydrogen ions in the foetus are carbonic and lactic acid from aerobic and anaerobic metabolism, respectively. The removal of $\mathrm{CO}_{2}$ (and so carbonic acid) from the foetus depends almost entirely on the placenta. The 
increased lactate is explained by increasing production from anaerobic metabolism. To determine the threshold of metabolic acidosis at delivery associated with newborn complications, Low et al. ${ }^{[22]}$ monitored 3 groups defined by umbilical artery base deficit at birth, with 4 to $8 \mathrm{mmol} / \mathrm{L}, 8$ to $12 \mathrm{mmol} / \mathrm{L}$, and 12 to 16 $\mathrm{mmol} / \mathrm{L}$. Moderate and severe newborn encephalopathy and respiratory complications and composite complication scores $>3$ were increased in the group with an umbilical artery base deficit of 12 to $16 \mathrm{mmol} / \mathrm{L}$. Moderate or severe newborn complications occurred in $10 \%$ of newborns in the same group, whereas such complications occur in $40 \%$ of neonates with an umbilical artery base deficit $>16 \mathrm{mmol} / \mathrm{L}$ at birth.

Acidosis may not lead to acidaemia, depending on the patient's ability to compensate. Compensation is a response to the primary disorder, attempting to bring the $\mathrm{pH}$ as close as possible to neutral ${ }^{[6]}$. Its response to hypoxia is influenced by factors that include foetal reserve, maturity and growth. Some foetuses can tolerate low oxygen saturation without a decreasing in the base excess. Acidosis is the most sensitive reflection of birth asphyxia, the absence of acidaemia rules out asphyxia. In the literature, the lower limits of normal for umbilical artery $\mathrm{pH}$ and base excess are 7.04-7.10 and $12 \mathrm{mmol} / \mathrm{L}$, respectively ${ }^{[23]}$.

Events of asphyxia during birth are common in piglets, and are diagnosed by the presence of metabolic acidosis, hyperlactemia and hypoxia ${ }^{[21,24]}$. Neonatal asphyxia delays the first contact with the udder and the first colostrum intake, and is associated with a reduction of rectal temperature at 24 hours of life, growth rate, and survival over 10 days, these criteria being of prognostic value for early postnatal vitality ${ }^{[19]}$. On the matter, Herpin et al. ${ }^{[25]}$ indicated that oxygen inhalation is effective in increasing oxygen tension in piglet arteries, and the ensuing prevention of the postnatal increase in blood lactate levels indicates that this enhanced oxygen supply is effective at the cellular level. Piglets rely almost exclusively on carbohydrate stores at birth, and it is assumed that this huge and immediate supply of oxygen stimulates oxidative metabolism and the complete aerobic oxidation of glucose at the cost of lactate production, thereby providing the animal with an extra amount of ATP. Lactate accumulation depends on the rate of glycolysis, the exchange of lactate across cell membranes, washout by the circulation, and consumption and clearance by tissues. Lactate clearance by the liver and other organs may be reduced in sepsis and in respiratory alkalosis. In human medicine, hyperlactatemia associated with metabolic acidosis is a major predictor of mortality of patients with sepsis or after cardiovascular. In patients with septic shock, serial determinations of blood lactate levels are good predictors of the development of multiple system organ failure and death. In this respect, the duration of lactic acidosis is more important than the initial lactate figure.

Although a number of factors may contribute to hyperlactatemia, these observations are compatible with a direct role of prolonged tissue hypoxia in the development of complications following septic shock ${ }^{[26]}$. In pre-term neonates were measured lactate, arterial $\mathrm{pH}$, and base excess in 75 mechanically ventilated newborns, most of whom were premature. Results showed a significantly higher blood lactate in those who died compared with survivors. After a neonate developed hyperlactatemia (defined as a blood lactate $>2.5 \mathrm{mmol} / \mathrm{l}$ ), a substantial fall in lactate was more likely to occur in survivors ${ }^{[27]}$. It is therefore likely that the reduction of lactate accumulation induced by oxygen inhalation could increase the ability for sustained muscular contractions, with beneficial effects on both physical activity and temperature regulation (shivering thermogenesis) in the piglets ${ }^{[28]}$. However, resuscitation of hypoxemic newborn piglets with $100 \%$ oxygen is associated with an increase in oxygen delivery and oxidative stress, and may be associated with the development of small intestinal hypoxiareoxygenation injury ${ }^{[25]}$. Resuscitation of asphyxiated newborns with lower oxygen concentrations may help to decrease the risk of necrotizing enterocolitis ${ }^{[29]}$. At reoxygenation, arterial oxygen pressure $\left(\mathrm{PaO}_{2}\right)$ quickly normalized in the room air group, but reached supranormal values in the $100 \% \mathrm{O}_{2}$ group. Potentially toxic amounts of free oxygen radicals like superoxide radicals and highly reactive hydroxyl radicals may be produced during reoxygenation of hypoxic ischemic tissue ${ }^{[30]}$.

A number of studies have pointed out the importance of body and room temperature for piglet vitality ${ }^{[8,31]}$. During progressive hypothermia the newborn piglet displays adequate metabolic responses as long as its body temperature is above $34^{\circ} \mathrm{C}$. Accordingly, shivering intensity is related to body and skin temperature during moderate hypothermia, this relation being weaker and not significant during deep hypothermia. Metabolic and physiological alterations induced directly or indirectly by body cooling are usually reversible in appropriate environmental conditions. Changes in circulating levels of energy substrates and hormones were fairly well related to the progressive changes in heat production and shivering occurring during body cooling ${ }^{[32]}$. Excessive hypothermia due to severe environmental conditions, decrease body weight or vitality at birth could reduce 
piglet vigour and colostrum intake and lead, ultimately, to the death of the animal ${ }^{[33]}$. Recently, Orozco et al. (unpublished data) reported that in newborn pigs during the first minute of life, the $\mathrm{pH}$ and body temperature values were dramatically elevated. Plasma glucose levels, calcium, lactate and $\mathrm{pCO}_{2}$, were significantly greater in the group of surviving piglets after an asphyxia episode compared with control group without asphyxia. Pigs born without asphyxia showed blood gas values of $\mathrm{pH}: 7.16$ (7.00-7.26), $\mathrm{PaO}_{2}: 26.4 \pm 17.7 \mathrm{mmHg}$, $\mathrm{PaCO}_{2}: \quad 60.4 \pm 18.7 \mathrm{mmHg}$, and $\mathrm{HCO}_{3}: 22.5 \pm 3.8$ $\mathrm{mmol} / \mathrm{L}$. In addition to other indicators of the energy metabolism like: lactate $65.3 \pm 15.5 \mathrm{mg} / \mathrm{dL}$, glucose $89.3 \pm 11.4 \mathrm{mg} / \mathrm{dL}$; serum electrolytes: sodium $138.1 \pm 3.3$ $\mathrm{mEq} / \mathrm{L}$, potassium $7.1 \pm 2.4 \mathrm{mEq} / \mathrm{L}$, as well as calcium $1.5 \pm 0.2 \mathrm{mEq} / \mathrm{L}$, and haematocrit $34.8+5.3 \%$ values.

On the other hand, values of $\mathrm{PaO}_{2}$ and $\mathrm{SaO}_{2}$ may also be lower in premature infants, caused by reduced lung function and a high altitude, by reduced inspired oxygen tension normal values for arterial blood gases are very dependent on postnatal age. Blood gas measurements and complementary, noninvasive monitoring techniques provide the clinician with information essential to patient assessment, therapeutic decision making, and prognostication ${ }^{[6]}$.

\section{ALTERNATIVES TO RESTORE THE ACID BASE BALANCE STATUS IN THE NEWBORN WITH PERINATAL ASPHYXIA}

The general goals of oxygen therapy in the neonate are to maintain adequate $\mathrm{PaO} 2$ and $\mathrm{SaO} 2$, and to minimize cardiac work and the work of breathing. It is important to realize that "optimal oxygenation" will result in different $\mathrm{PaO} 2 / \mathrm{SaO} 2$ goals for different types of neonatal patients. Most commonly, premature infants in respiratory failure should have $\mathrm{PaO} 2$ values between 6.66 and $10.66 \mathrm{kPa}(50-80 \mathrm{mmHg})$. These goals minimize the chances of blindness caused by retinopathy of prematurity and lower the inspired $\mathrm{O} 2$ and airway pressure requirements that, if higher, might increase the likelihood of bronchopulmonary dysplasia (BPD). By contrast, full-term infants with diaphragmatic hernia or persistent pulmonary hypertension may require $\mathrm{PaO} 2$ values of $10.66-13.33$ $\mathrm{kPa}$ (80-100 $\mathrm{mmHg}$ ) to maintain stability, minimize pulmonary resistance, and avoid worsening pulmonary hypertension. Infants with BPD or chronic lung disease show improved growth and less pulmonary hypertension (cor pulmonale) when $\mathrm{SaO} 2$ is kept $>92 \%$ during wakefulness, sleep, and feeding. Liberal use of supplemental oxygen may be deleterious by promoting ductus arteriosus closure in some infants with congenital heart disease, such as hypoplastic left heart, by lowering pulmonary vascular resistance in other infants with large left-to-right shunts ${ }^{[6]}$.

Blood sampling from the umbilical cord at the time of delivery is an important mean of documenting foetal blood gas and acid-base status at birth and for assessing hemoglobin levels. However, the sampling of umbilical cord blood is sometimes limited by small sample volumes at delivery, especially from the umbilical artery. Placental chorionic plate vessels provide for another source of foetal blood that can be sampled for blood gas, $\mathrm{pH}$, and hemoglobin measurements, but only after delivery of th placenta, which may be several minutes after delivery of the infant and clamping of the umbilical circulation. Continued blood gas exchange across the placenta, metabolism by the placenta, and fluid shifts within the placenta, might then affect these placental blood measurements ${ }^{[34]}$.

An interesting solution in pigs that underwent asphyxia could be the increase oxygen inhalation. Studies made by Herpin et al. ${ }^{[25]}$, after only 2 to $3 \mathrm{~min}$ in the oxygen-controlled chamber, indicated a pronounced rise in blood $\mathrm{pO}_{2}$ demonstrating that oxygen inhalation is effective in increasing oxygen tension in piglet arteries, and the ensuing prevention of the postnatal increase in blood lactate levels indicate that this enhanced oxygen supply is effective at the cellular level. Zaleski and Hacker [35,36], provided oxygen inhalation to the sow at a rate of $6 \mathrm{~L} / \mathrm{min}$ showing no effectiveness in reducing stillbirth rate nor in improving pig viability. Neither viability scores nor pig venous blood gases were affected by treatment. Herpin et al. ${ }^{[25]}$, administered oxygen inhalation to the piglet immediately after birth (40\% oxygen for $20 \mathrm{~min}$ ) and observed affection on piglet metabolism through stimulation of oxidative metabolism (reduction of circulating levels of lactate) and lowering of the level of postnatal hypothermia (particularly for the lightest pigs), oxygen inhalation increased piglet viability and reduced mortality during the first day of life by $75 \%$ (2 vs. $8 \%$ ). No additional effects were observed during the following days and overall mortality between birth and weaning at 21 days was reduced from 12 to $8 \%$. The reduction of mortality rate was only observed for lowbirth weight piglets and during the first day of life, the most crucial for piglet survival. This result is consistent with previous observations showing that light piglets are more likely to experience neonatal asphyxia ${ }^{[19]}$. In another study, Tølløfsrud et al. ${ }^{[30]}$ did not find significant differences between the room air and the $\mathrm{O}_{2}$ groups during $120 \mathrm{~min}$ of reoxygenation in mean arterial blood pressure, pulmonary arterial pressure, cardiac index, base excess, or plasma hypoxanthine. 
They showed that hypoxic newborn piglets with meconium aspiration were found to be reoxygenated as efficiently with room air as with $100 \%$. The authors noticed that the degree of maturity of the pigs probably is more important that the body weight. On the other hand, Aaltonen et al. ${ }^{[37]}$, showed in newborn piglets that systemic arterial pressure and vascular resistance remained in the control level (o "baseline levels") after meconium instillation alone, and asphyxia (with and without pulmonary meconium insult) resulted in a sustained fall in the systemic pressure.

Human neonatal resuscitation following birth asphyxia is traditionally carried out with $100 \%$ oxygen. For babies born at term, the guidelines recommend the use of $100 \%$ supplemental oxygen when a baby is cyanotic or when positive pressure ventilation is required during neonatal resuscitation. However, research suggests that resuscitation with something less than $100 \%$ may be just as successful. If resuscitation is started with less than $100 \%$ oxygen, supplemental oxygen up to $100 \%$ should be administered if there is no appreciable improvement within 90 seconds following birth. If supplemental oxygen is unavailable, use room air to deliver positive-pressure ventilation ${ }^{[38]}$.

Oxygen is required to sustain life, but too much oxygen is toxic to the mammalian central nervous system (CNS) due to excessive production and accumulation of reactive oxygen species (ROS). Recall that "oxygen pressure in the mammalian CNS is maintained at a level which is sufficiently high to ensure undisturbed function of brain cells and sufficiently low to minimize generation of free radicals" ${ }^{[39]}$. Hyperoxia is defined as any level of $\mathrm{PO}_{2}$, inspired (in vivo) or superfusate (in vitro), that produces a neural tissue $\mathrm{pO}_{2}$ $\left(\mathrm{Pti}_{\mathrm{O} 2}\right)$ greater than the range of $\mathrm{Pti}_{\mathrm{O} 2}$ values that occur in an animal breathing normobaric air $\left(\mathrm{PI}_{\mathrm{O} 2}\right.$ of $\approx 160$ Torr). Depending on the region of the CNS, normoxic values for $\mathrm{Pti}_{\mathrm{O} 2}$ will range from a minimum of $\sim 3$ Torr up to a maximum of $\approx 35$ Torr). Therefore, we will consider any value of $\mathrm{Pti}_{\mathrm{O} 2}>35$ Torr $\left(\mathrm{PI}_{\mathrm{O} 2}\right.$ of $>160$ Torr $)$ as hyperoxic and capable of increasing ROS levels in the brain stem. During hyperoxia, as $\mathrm{Pti}_{\mathrm{O} 2}$ increases, the body's antioxidant defenses are overwhelmed by increased production of ROS in the mitochondria, nucleus, cytosol, membranes, and extracellular fluid compartments. ROS include various $\mathrm{O}_{2}$ free radicals and their reactive by-products, such as superoxide, hydrogen peroxide, hydroxyl radicals, nitric oxide, and peroxynitrite $^{[40]}$.

With respect to gas exchange, ventilation with noninvasive motion ventilation (NIMV) after meconium aspiration results as effective as conventional mechanical ventilation or high-frequency ventilation.
However, NIMV provides the added beneficial effects of reduction of pulmonary vascular resistance and mean airway pressures. This may have beneficial effects during meconium aspiration and other pulmonary diseases associated with reduced compliance ${ }^{[41]}$.

Herpin et al. ${ }^{[25]}$ have calculated that oxygen inhalation might allow producers to raise 1.1 extra pigs per sow. The economic benefits of this procedure would be maximized when several litters are being born simultaneously and may offset the extra labor at farrowing time.

Inhaled nitric oxide (NO) was recently approved by the Food and Drug Administration for use in neonates with hypoxemic respiratory failure and persistent pulmonary hypertension. Associated with this approval, we can expect an increase in not only the acute usage of inhaled NO for patients with pulmonary hypertension but potential chronic usage as well ${ }^{[42]}$. Currently there is considerable evidence that the regulation of vascular muscle tone at the cellular level occurs via NO. Nitric oxide is generated enzymatically by one of several NO synthases from L-arginine. NO activates guanyl cyclase by binding to its haeme component leading to the production of cyclic guanosine monophosphate (cGMP). The mechanism by which cyclic GMP relaxes vascular smooth muscle is not clear, but probably involves inhibition of activation-induced elevation in cytosolic calcium concentration. It appears reasonable to use NO in an initial concentration of $20 \mathrm{ppm}$ for term and near term infants with hypoxic respiratory failure who do not have a diaphragmatic hernia [43]. Methaemoglobinaemia is a known potential complication of inhaled NO. Methaemoglobin reduces the oxygen carrying capacity of the blood and shifts the oxyhaemoglobin dissociation curve to the left which impairs the unloading of oxygen to the tissues ${ }^{[44]}$. The recent use of inhaled NO to treat pulmonary hypertension in the newborn and in older patients has refocused attention on methaemoglobinaemia. Inhaled nitric oxide binds to haemoglobin rapidly in the pulmonary circulation, resulting in selective relaxation of pulmonary vascular smooth muscle. The nitric oxidehaemoglobin complex is converted to methaemoglobin, and toxic concentrations of $\mathrm{NO}$ can result in methaemoglobinaemia. To date, methaemoglobinaemia has not been a serious problem in neonates receiving 5 $80 \mathrm{ppm}$ of inhaled nitric oxide. Intermittent COoximeter measurements of methaemoglobin should be performed in patients receiving inhaled $\mathrm{NO}$, especially at concentrations $>40 \mathrm{ppm}$, to keep methaemoglobin concentrations $<5 \%$ of total haemoglobin ${ }^{[6]}$.

Renal compensation causes bicarbonate retention, bringing the $\mathrm{pH}$ back towards normal, but compensation 
is usually not complete, that is, $\mathrm{pH}$ remains $<7.40$. Diuretics are used to improve lung mechanics, to decrease lung water, and to improve gas exchange. Thiazide and especially loop diuretics result in a loss of chloride, potassium, and sodium, and in retention of bicarbonate. When high doses of diuretics are used without salt replacement, metabolic alkalosis may result, with $\mathrm{pH}$ values $>7.40$. Under these circumstances, respiratory drive can be depressed, worsening the hypoventilation. Lowering the dose of diuretics, changing from a loop to a thiazide diuretic, replacement of salt, or use of acetazolamide to lower plasma bicarbonate are strategies that can be used to minimize this problem ${ }^{[6]}$.

Recently in a retrospective study made in full-term newborn with severe perinatal asphyxia, Shah et al. ${ }^{[45]}$ showed that the highest recorded lactate level in the first hour of life and serial measurements of lactate are important predictors of moderate-to-severe hypoxic ischaemic encephalopathy. The evolution of the lactate concentration after therapeutic management is able to predict more accurately the outcome. Intervention for the stressed foetus in utero and the ability to provide adequate cardiopulmonary support ex utero, contributed substantively to improved perinatal outcomes. Measurements of blood pressure, perfusion, cardiac output, oxygen saturation, $\mathrm{pH}, \mathrm{PCO}_{2}$ and $\mathrm{PO}_{2}$ provided a rational basis for therapies that enhanced survival. Perinatal respiratory adaptation, allowed a previously unattainable rationality to the observation and care of premature and newborn infants during the sometimes prolonged period of cardiopulmonary instability accompanying premature or complicated birth. Arterialvenous access, microchemistry, support of blood pressure, thermal regulation, and nutrition all contributed to the improvements in perinatal care ${ }^{[46]}$. Sánchez-Aparicio ${ }^{[47]}$ used sildenafil citrate in near-term pregnant guinea pigs, trying to improve maturation of foetal organs and tolerance to perinatal asphyxia. Also, he evaluated tolerance to perinatal asphyxia by blood gas measurements.

\section{CONCLUSIONS}

Care of the sick newborn requires the best instrumentation complemented by thorough clinical vigilance. Arterial blood gas analyses are essential to monitor gas exchange in perinatal asphyxia and critically ill patients. Intra-partum asphyxia in pigs is related with an evident combination of metabolic and respiratory acidosis, these acid-base changes can start quickly once the pigs begin to breathe. Blood gas test is an excellent tool to assess pulmonary gas exchange and acid-base status. Umbilical cord gases are used as an indicator of foetal oxygenation just prior to birth, cord arterial blood normally reflects foetal acid-base balance while venous blood reflects a combination of maternal acid-base status and placental fun, whereas Apgar score reflects newborn adaptation after birth. However, neither of these assessments is a reliable predictor of long-term neurologic outcome. The decision to obtain blood gases must be weighed by the individual clinician against the potential benefits.

Strategies to treat to prevent or treat perinatal asphyxia should explore the efficacy of combination therapies, because it is unlikely that a single agent will effectively inhibit the complex and dynamic cascades of hypoxic-ischemic injury. Future treatments, which hold promise or offer a novel approach to treat hypoxicischemia, urgently need a collective effort to find practical solutions because perinatal hypoxic ischemia is the most common cause of neurologic disease during the neonatal period and it is associated with a high mortality and morbidity rate. The goal should be the reduction of perinatal asphyxia and mortality.

\section{ACKNOWLEDGMENTS}

The study was supported by a grant from the Programa de Mejoramiento del Profesorado (PROMEPSEP) No. UAM-PTC-028 to the Academic Staff of "Etología, Production Porcina y Fauna Silvestre". Daniel Mota-Rojas, María Alonso-Spilsbury, María E. Trujillo and Rafael Hernández-González were suported, as members, by the Sistema Nacional de Investigadores in Mexico. Authors are indebt with Q. Antonio Campos Osorno, Chief of the Branch of Gasometry at I.L. Diagnósticos S.A. de C.V., México DF, for temporarily providing the equipment for blood gas and electrolytes analyses, and with QFB Mario Alberto García Piña for his professional support in the installation and verification of the instrument as well as for the time he devoted to capacitate us for using it.

\section{REFERENCES}

1. James, L.S., I.M. Weisbrot, C.E. Prince, D.A. Holaday and W. Apgar, 1958. The acid-base status of human infants in relation to birth asphyxia and the onset of respiration. The Journal of Pediatrics, 52379-394.

2. ACOG, 2003. Task Force on Neonatal Encephalopathy and Cerebral Palsy: Defining the Pathogenesis and Pathophysiology. Staff American College of Obstetricians and Gynecologists with American Academy of Pediatrics Staff. The American College of Obstetricians and Gynecologists., Washington, DC. 
3. Victory, R., D. Penava, O. Da Silva, R. Natale and B. Richardson, 2004. Umbilical cord $\mathrm{pH}$ and base excess values in relation to adverse outcome events for infants delivering at term. American Journal of Obstetrics and Gynecology, 191(6):2021-2028.

4. Nelson, K.B. and J.H. Ellenberg, 1981. Apgar score predictors of chronic neurologic disability. Pediatrics, 6836-44.

5. Sykes, G.S., P.M. Molloy, P. Johnson, W. Gu, F. Ashworth, G.M. Stirrat and A.C. Turnbull, 1982. Do Apgar scores indicate asphyxia? Lancet, 1(8270):494-496.

6. Brouillette, R.T. and D.H. Waxman, 1997. Evaluation of the newborn's blood gas status. Clinical Chemistry, 43215-221.

7. Williams, P.K. and A. Singh, 2002. The correlation of seizures in newborn infants with significant acidosis at birth with umbilical artery cord gas values. Obstetrics and Gynecology, 100(3):557560.

8. Malmkvist, J., L.J. Pedersen, B.M. Damgaard, K. Thodberg, E. Jørgersen and R. Labouriau, 2006. Does floor heating around parturition affect the vitality of piglets born to loosed housed sows? Applied Animal Behavior Science, 99(1-2):88-105.

9. Kolb, E., 2004. Biochemical and pathobiochemical aspects of the development and prophylaxis of piglet losses: A review. Prak. Tierarzt., 85(5):356364.

10. van Dijk, A.J., T. van der Lende and M.A.M. Taverne, 2006. Acid-base balance of umbilical artery blood in liveborn piglets at birth and its relation with factors affecting delivery of individual piglets. Theriogenology, 661824-1833.

11. González de Dios, J., 2002. Definition of perinatal asphixia inmedical literature: the need of a consensus. Revista de Neurología, 35(7):628-634.

12. Askin, D.F., 1997. Interpretation of neonatal blood gases. Part II: disorders of acid-base balance. Neonatal Network, 16(6):23-29.

13. Bobrow, C.S. and P.W. Soothill, 1999. Causes and consequences of fetal acidosis. Archives of Disease in Childhood. Fetal and Neonatal Edition, 80246249.

14. Yeomans, E.R., J.C. Hauth, L.C. Gilstrap III and D.M. Strickland, 1985. Umbilical cord pH, $\mathrm{PCO}_{2}$, and bicarbonate following uncomplicated term vaginal deliveries. American Journal of Obstetrics and Gynecology, 151798-800.

15. Thorp, J.A., J.E. Sampson, V.M. Parisi and R.K. Creasy, 1989. Routine umbilical cord gas determinations. American Journal of Obstetrics and Gynecology, 161600-605.
16. Laczna, K.M., K. Källén, K. Marsál and P. Olofsson, 2003. Gestational age-dependent reference values for $\mathrm{pH}$ in umbilical cord arterial blood at term. Obstetrics and Gynecology, 102338-345.

17. Belai, Y., T.M. Goodwin, M. Durand, J.S. Greenspoon, R.H. Paul and F.J. Walther, 1998. Umbilical arteriovenous $\mathrm{PO}_{2}$ and $\mathrm{PCO} 2$ differences and neonatal morbidity in term infants with severe acidosis. American Journal of Obstetrics and Gynecology, 17813-19.

18. Buthani, V.K., 2006. Pulmonary gas exchange. In: Manual and Neonatal Care (eds S. M. Donn and S. K. Sinha) pp. 29-36. Mosby Inc., Philadelphia.

19. Herpin, P., J. Le Dividich, J.C. Hulin, M. Fillaut, F. de Marco and R. Bertin, 1996. Effects of the level of asphyxia during delivery on viability at birth and early postnatal vitality of newborn pigs. Journal of Animal Science, 742067-2075.

20. Chiang, F.E. and R.G. Rodway, 1997. Determinations of umbilical cord Beta-endorphin concentration and blood gas parameters in newborn piglets. Research in Veterinary Science, 63107-111.

21. Herpin, P., F. Wosiak, J. Le Dividich and R. Bertin, 1998. Effects of acute asphyxia at birth on subsequent heat production capacity in newborn pigs. Research in Veterinary Science, 66(1):45-49.

22. Low, J.A., B.G. Lindsay and E.J. Derrick, 1997. Threshold of metabolic acidosis associated with newborn complications. American Journal of Obstetrics and Gynecology, 1771391-1394.

23. Arikan, G.M., H.S. Scholz, M.C.H. Haeusler, A. Giuliani, J. Haas and P.A.M. Weiss, 2000. Low fetal oxygen saturation at birth and acidosis. Obstetrics and Gynecology, 95565-571.

24. English, P.R. and V. Wilkinson, 1982. Management of the sow and litter in late pregnancy and lactation in relation to piglet survival and growth. In: Control of Pig Reproduction (eds D. J. A. Cole and G. R. Foxcroft) pp. 479-506. Butterworths, London.

25. Herpin, P., C.J. Hulin, J. Le Dividich and M. Fillaut, 2001. Effect of oxygen inhalation at birth on the reduction of early postnatal mortality in pigs. Journal of Animal Science, 795-10.

26. Bakker, J., P. Gris, M. Coffernils, R.J. Kahn and J.L. Vincent, 1996. Serial blood lactate levels can predict the development of multiple organ failure following septic shock. American Journal of Surgery, 171(2):221-226.

27. Deshpande, S.A. and P.M.P. Ward-Platt, 1997. Association between blood lactate and acid-base status and mortality in ventilated babies. Archives of Disease in Childhood, 76F15-F20. 
28. Duke, T., 1999. Dysoxia and lactate. Archives of Disease in Childhood, 81343-350.

29. Haase, E., D.L. Bigam, Q.B. Nakonechny, L.D. Jewell, G. Korbutt and P.-Y. Cheung, 2004. Resuscitation with $100 \%$ oxygen causes intestinal glutathione oxidation and reoxygenation injury in asphyxiated newborn piglets. Annals of Surgery, 240(2):364-373.

30. Tølløfsrud, P.A., A.B. Solas and O.D. Saugstad, 2001. Newborn piglets with meconium aspiration resuscitated with room air or $100 \%$ oxygen. Pediatric Research, 50(3):423-429.

31. Tuchscherer, M., B. Pippe, A. Tuchscherer and U. Tiemann, 2000. Early identification of neonates at risk: traits of newborn piglets with respect to survival. Theriogenology, 54(3):371-388.

32. Lossec, G., P. Herpin and J. Le Dividich, 1998. Thermoregulatory responses of the newborn pig during experimentally induced hypothermia and rewarming. Experimental Physiology, 83667-678.

33. Herpin, P. and J. Le Dividich, 1995. Thermoregulation and the environment. In: Neonatal Pig: Development and Survival (eds M. A. Varley) pp. 57-95. CAB International, Leeds, U.K.

34. Nodwell, A., L. Carmichael, M. Ross and B. Richardson, 2005. Placental compared with umbilical cord blood to assess fetal blood gas and acid-base status. Obstetrics and Gynecology, 5(1):129-138.

35. Zaleski, H.M. and R.R. Hacker, 1993. Effect of oxygen and neostigmine on stillbirth and pig viability. Journal of Animal Science, 71298-305.

36. Zaleski, H.M. and R.R. Hacker, 1993. Variables related to the progress of parturition and probability of stillbirth in swine. The Canadian Veterinary Journal, 34109-113.

37. Aaltonen, M., H. Soukka, L. Halkola, J. Jalonen, I.E. Holopainen, P. Kero and P.O. Kaapa, 2003. Asphyxia aggravates systemic hypotension but not pulmonary hypertension in piglets with meconium aspiration. Pediatric Research, 53473-478.

38. AAP/AHA. Summary of Major Changes to the 2005 AAP/AHA. Emergency Cardiovascular Care Guidelines for Neonatal Resuscitation: Translating Evidence-Based Guidelines to the NRP. http://www.aap.org/nrp/pdf/nrp-summary.pdf. 2005.
39. Erecinska, M. and I.A. Silver, 2001. Tissue oxygen tension and brain sensitivity to hypoxia. Respiration Physiology, 128263-276.

40. Dean, J.B., D.K. Mulkey, R.A. Henderson, S.J. Potter and R.W. Putnam, 2004. Hyperoxia, reactive oxygen species, and hyperventilation: oxygen sensitivity of brain stem neurons. Journal of Applied Physiology, 96(2):784-791.

41. Adams, J.A., M.J. Mangino, J. Bassuk and M.A. Sackner, 2000. Hemodynamic effects of periodic $\mathrm{Gz}$ acceleration in meconium aspiration in pigs. Journal of Applied Physiology, 892447-2452.

42. Mc Mullan, D.M., J.M. Bekker, M.J. Johengen, K. Hendricks-Munoz, R. Gerrets, S.M. Black and J.R. Fineman, 2001. Inhaled nitric oxide-induced rebound pulmonary hypertension: role for endothelin-1. American Journal of Physiology. Heart and Circulatory Physiology., 280(2):H777$\mathrm{H} 785$.

43. Finer, N.N. and K.J. Barrington. Nitric oxide for respiratory failure in infants born at or near term. Cochrane Database Syst Rev. Oct 18, (4):CD000399.Review. http://www.nichd.nih.gov/cochrane/finer/finer.htm. 2006.

44. Taylor, M.B., K.G. Christian, N. Patel and K.B. Churchwell, 2001. Methemoglobinemia: Toxicity of inhaled nitric oxide therapy. Pediatric Critical Care Medicine, 2(1):99-101.

45. Shah, S., M. Tracy and J. Smyth, 2004. Postnatal lactate as an early predictor of short-term outcome after intrapartum asphyxia. Journal of Perinatology, 2416-20.

46. Whitsett, A.J. and T.M. Stahlman, 1998. Impact of advances in physiology, biochemistry, and molecular biology on pulmonary disease in neonates. American Journal of Respiratory and Critical Care Medicine, 157(4):S67-S71.

47. Sánchez-Aparicio, P., 2007. Uso de sildenafil en cobayas gestantes y su efecto sobre el crecimiento uterino, desarrollo fetal y tolerancia a la asfixia en neonatos, evaluada a través de gasometría sanguínea. Tesis de Maestría en Ciencias de la Producción y de la Salud Animal. FMVZ-UNAM, México. 